\title{
Orchard Tractor Operator Dies When Run Over by Rotary Mower After Falling From Tractor

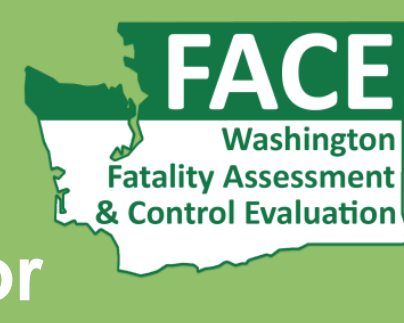

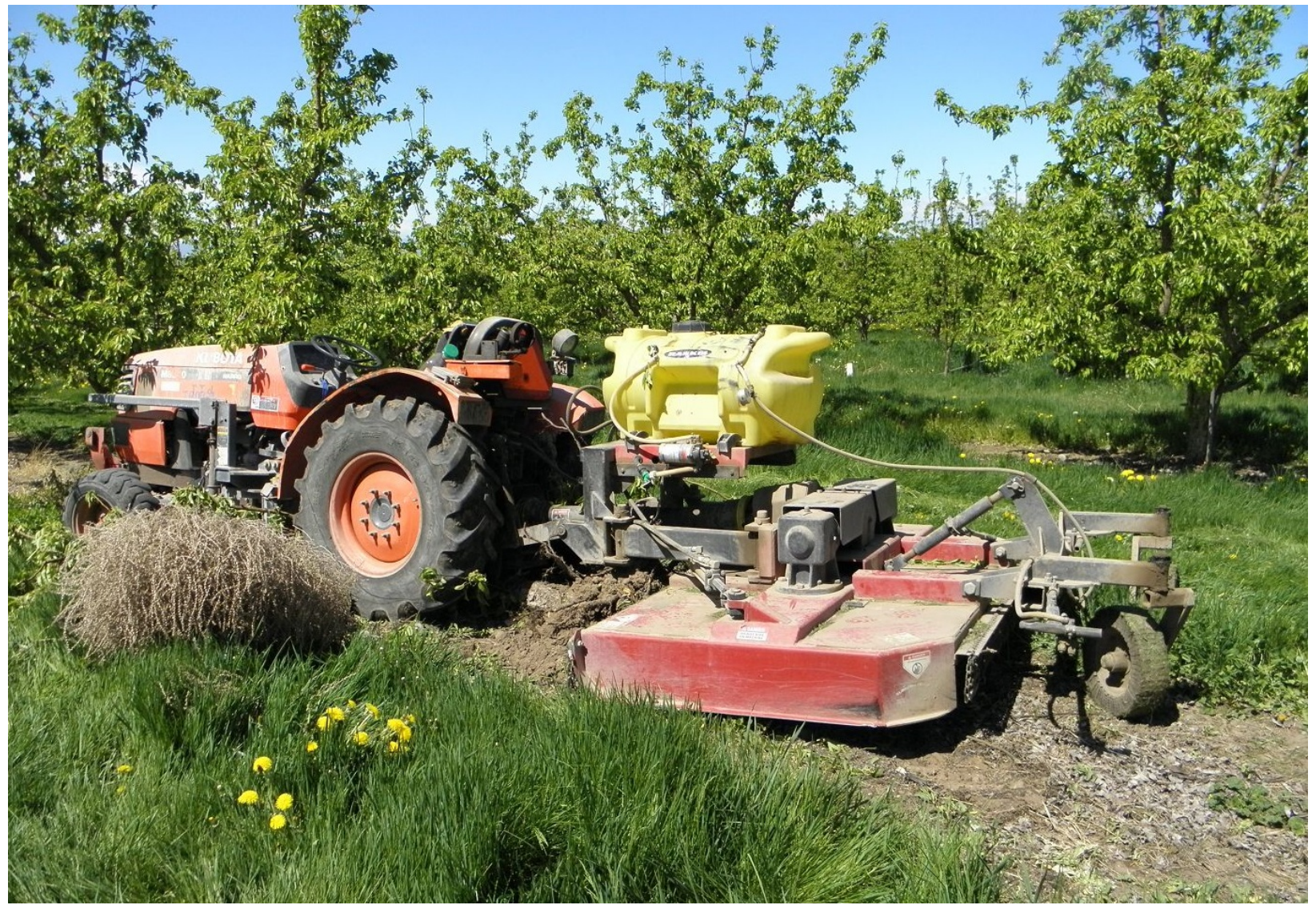

Investigation: 13WA01501

Release Date: May 24, 2017

SHARP Report: 52-40-2017 


\section{Table of Contents}

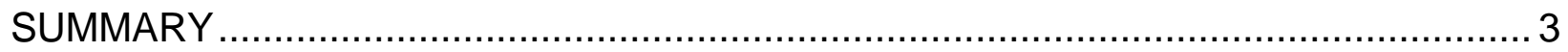

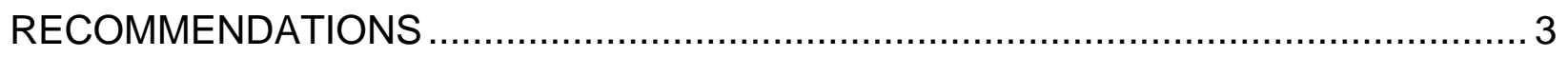

INTRODUCTION

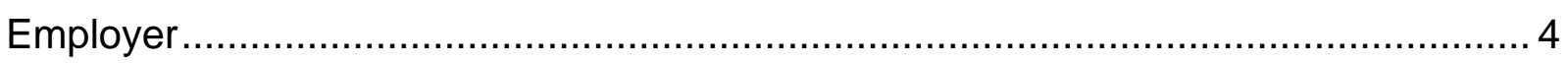

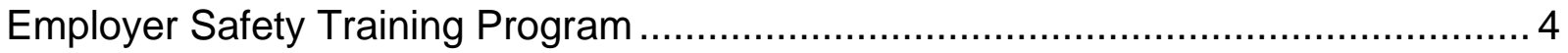

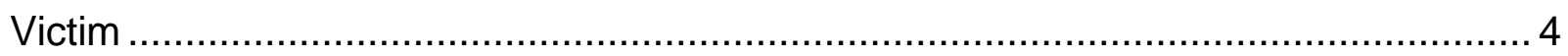

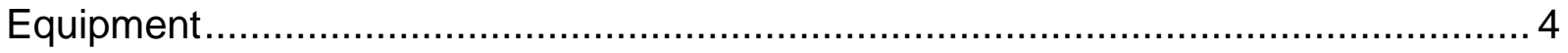

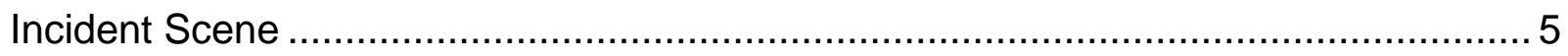

INVESTIGATION

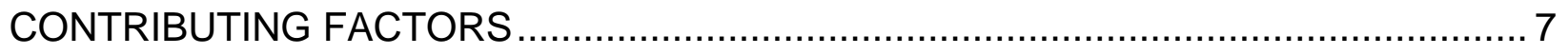

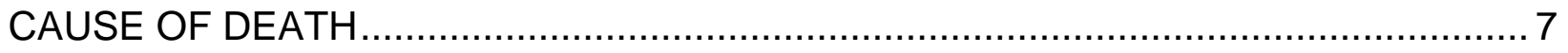

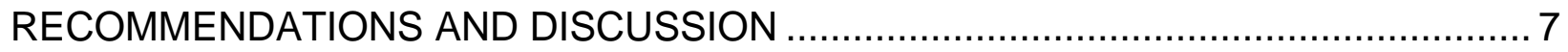

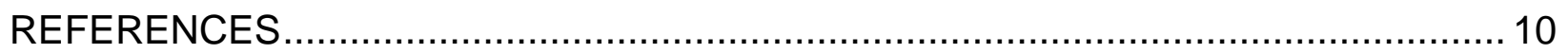

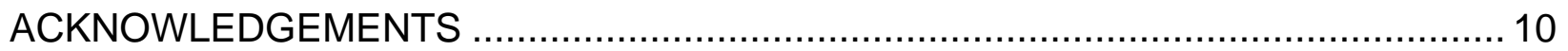

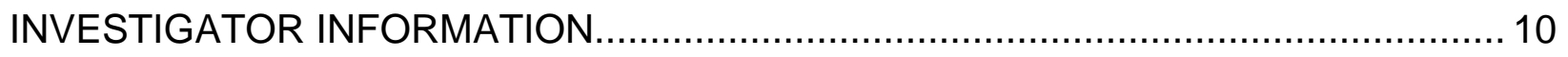

WASHINGTON STATE FACE PROGRAM INFORMATION ................................... 10 


\section{SUMMARY}

In April of 2013, an orchard worker died when he was run over by a rotary mower after he fell from the tractor it was attached to. The victim was using the tractor and mower attachment to cut the grass between rows of pear trees. The incident was not witnessed, but investigators believe that it is most probable that he fell when he attempted to dismount the tractor to retrieve his hat that may have been knocked off by a low hanging branch. He likely either failed to put the tractor in neutral when he stopped, causing the tractor to lurch forward when he removed his foot from the clutch pedal, or inadvertently moved the gear selector lever out of neutral as he stood up to dismount the tractor. In either scenario, it is assumed that the sudden or unexpected movement of the tractor caused him to fall to the ground between the tractor and the mower. As the tractor continued to move forward, the victim's upper body was run over by the $1740 \mathrm{lb}$. mower. He was pronounced dead at the scene.

\section{RECOMMENDATIONS}

- Train operators to always shut down tractors safely before leaving the driver's seat. Ensure that they follow safety guidelines through frequent retraining and spot checks.

- Train operators to always mount and dismount tractors in a safe manner by using all steps and handholds available, and maintaining three points of contact.

- Keep clear of obstacles, such as low hanging branches, to the extent possible when operating a tractor with or without attachments.

- Consider using tractors equipped with operator presence sensing (OPS) technology or other interlocks that will lock out the powertrain and PTO if the operator leaves the driver's seat. 


\section{INTRODUCTION}

In April of 2013, the Washington State Division of Occupational Safety and Health (DOSH) notified the Washington State Fatality Assessment and Control Evaluation (FACE) program of the death of a 25-year-old orchard laborer.

WA FACE investigators interviewed the safety director and tractor manager of the company where the victim had been employed. Documents reviewed during the course of this FACE investigation include the DOSH investigation file, Sheriff's office and State Patrol documents, equipment manufacturer information, and the death certificate.

\section{Employer}

The employer was a family owned fruit production and shipping company in business for over sixty years. They employed approximately 40 workers at the time of the incident.

\section{Employer Safety Training Program}

The employer had a written safety program and held monthly safety meetings. Tractor safety training was conducted yearly.

At the time of the incident, the victim had been provided and signed-off on written tractor safety material twice since beginning employment. The material was presented in both English and Spanish, and included "Use handrails when getting on and off the tractor" and "When tractor is stopped, set brakes securely and use park lock".

\section{Victim}

The victim was a 25-year-old orchard tractor operator. He had been working for the employer for approximately five months. He had frequently operated the tractor with the mower attachment at the orchard. Originally from Mexico, he had lived in the United States for three years. He had family in the area, and was expecting his first child with his partner.

\section{Equipment}

The tractor that the victim was operating at the time of the incident was a 1999 Kubota Narrow M8200 tractor equipped with ROPS (rollover protection structure). The ROPS was not deployed at the time of the incident.

The mower attachment was a Tebben model TC94-700 variable offset rotary cutter. The mower was 47.5 inches long and 7 feet wide, and weighed approximately $1740 \mathrm{lbs}$. Front and rear chain guards were attached to the mower. The mower was capable of operating with a 14-inch offset, allowing the operator to cut nearer the tree line while avoiding low hanging branches while driving, but it was not side shifted in this way at the time of the incident. 


\section{Incident Scene}

The incident occurred in a level section of the orchard where pears were grown. Rows of pear trees ran east to west.

Figure 1. Diagram of incident scene
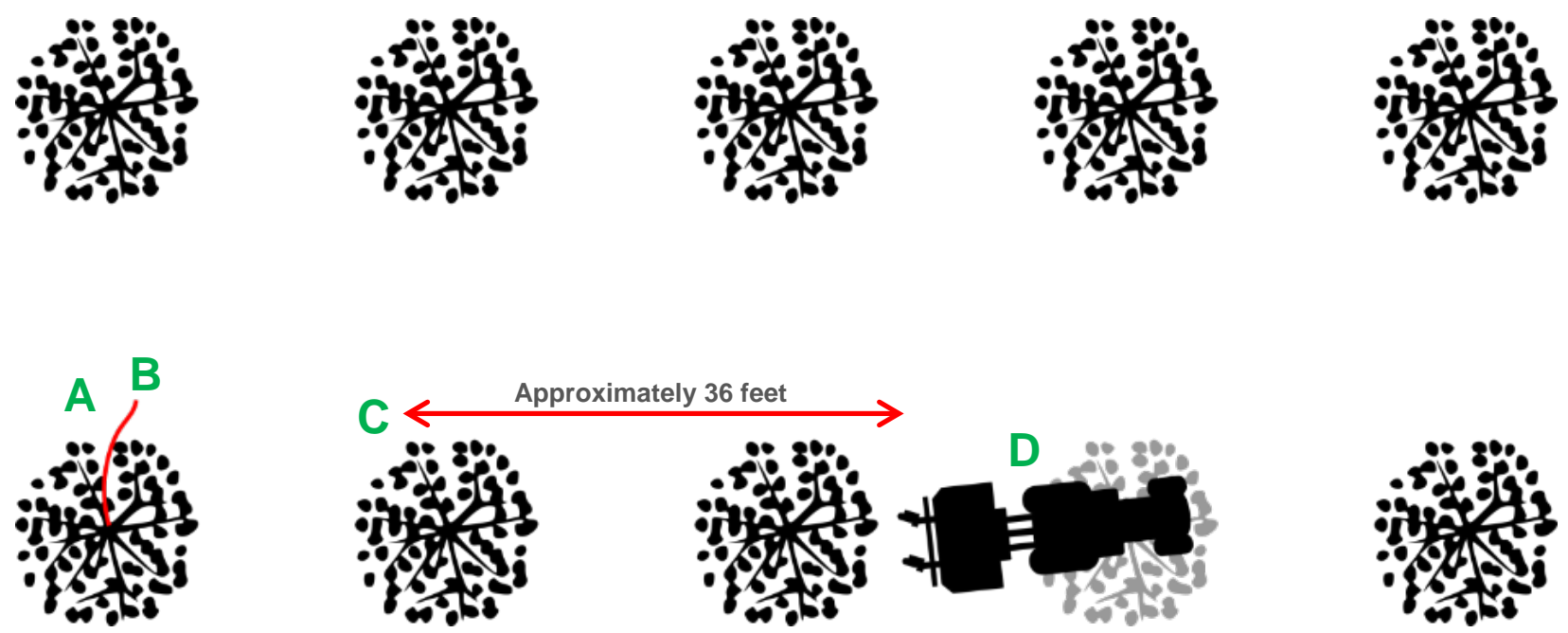
A. Location of victim's hat
B. Location of low hanging branch thought to have struck victim
C. Location of victim
D. Location where tractor came to a stop after pushing over and becoming stuck on a pear tree

\section{INVESTIGATION}

On the morning of the incident, the victim's supervisor, who was the tractor manager of the orchard, needed to go into town to get some parts. Before he left, he asked the victim to do a task using a specific tractor. When he returned around 10:00 a.m., he noticed that the tractor he had asked the victim to use had not been moved. The tractor manager asked another employee where the victim had gone. The employee told him that the victim was mowing grass in the pear section of the orchard using another tractor, and that he had seen him in one of the rows. When the tractor manager looked toward the area mentioned by the employee, he noticed that the tractor was not moving and assumed that the victim was taking a break. He began driving toward the victim's location in his work truck as the other employee drove down on another tractor.

When the tractor manager neared the victim's location, he saw the victim lying on the ground. He was severely injured, with large cuts on the back of his head and arms. It appeared that he had been run over by the mower attachment. The tractor and mower had continued moving until running into a pear tree two trees away from where the victim was lying. The tractor was stuck on the tree, still running in gear with the right 


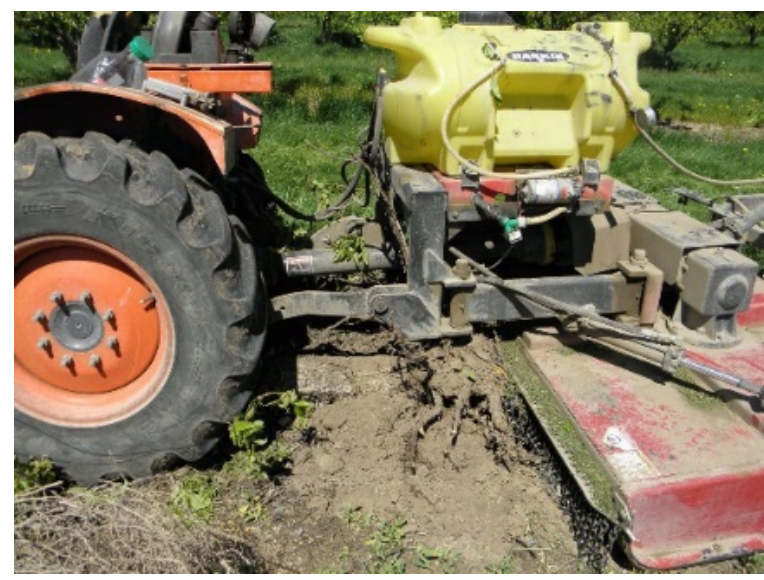

Photo 1: Position of tractor and mower after pushing over and becoming stuck on a pear tree

rear tire still turning (Photos 1 and 2). While the other employee stayed with the victim, the tractor manager went to the tractor and shut it off by pulling the engine stop and removing the key, and then called 911. Emergency responders arrived and began $\mathrm{CPR}$, but the victim was declared dead at the scene.

An investigation of the site found the victim's hat on the ground approximately one tree east of his position. Investigators believe that the hat may have been knocked off the victim by a low hanging branch on the tree above where it was found (Photo 3). The grass between the victim and the location of the tractor and mower was uncut, suggesting that the victim had disengaged the mower blades before he fell from the tractor. It was also determined that the mower was not being operated in the offset position designed to allow the operator to maintain more distance between the tractor and the trees while mowing.

At the time of the incident, the tractor's foldable rollover protective structure (ROPS) was in the down position (Photo 4). In Washington State, the orchard work being performed was exempt from ROPS requirements.

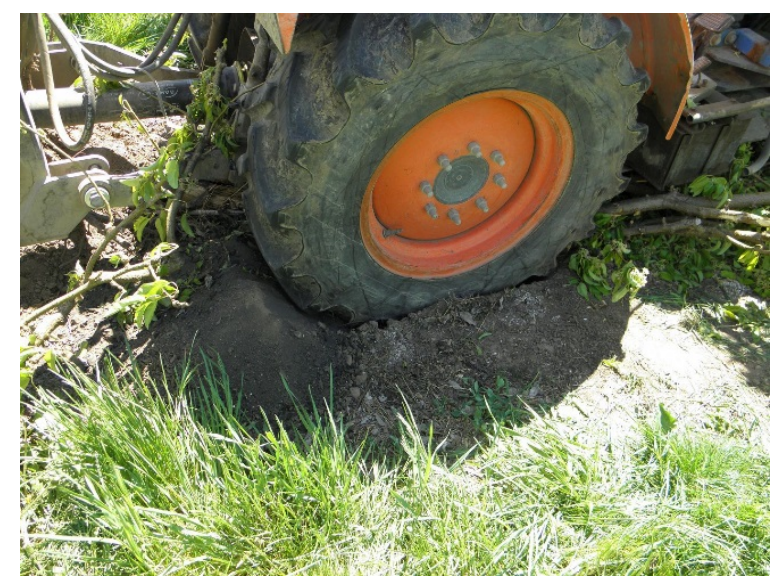

Photo 2: Right rear tire that continued turning after tractor ran over and became stuck on tree

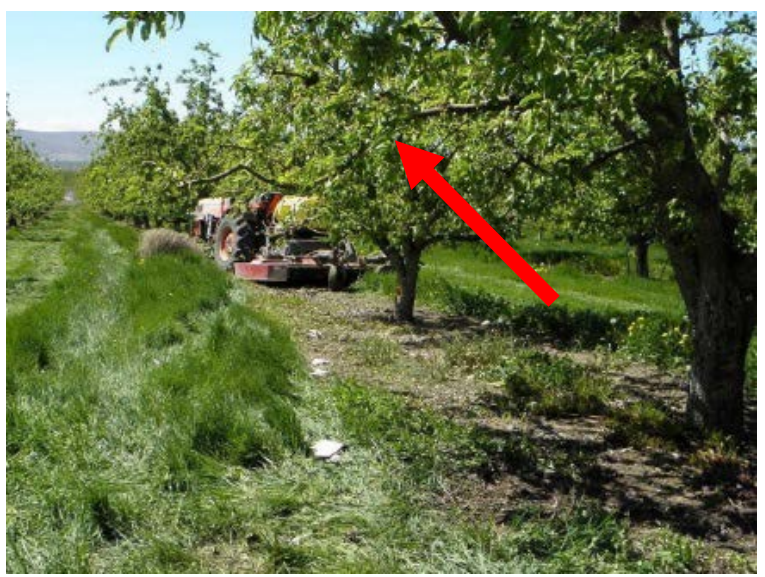

Photo 3: View of tractor from position of victim. Arrow indicates low-hanging branch that may have knocked victim's hat to the ground

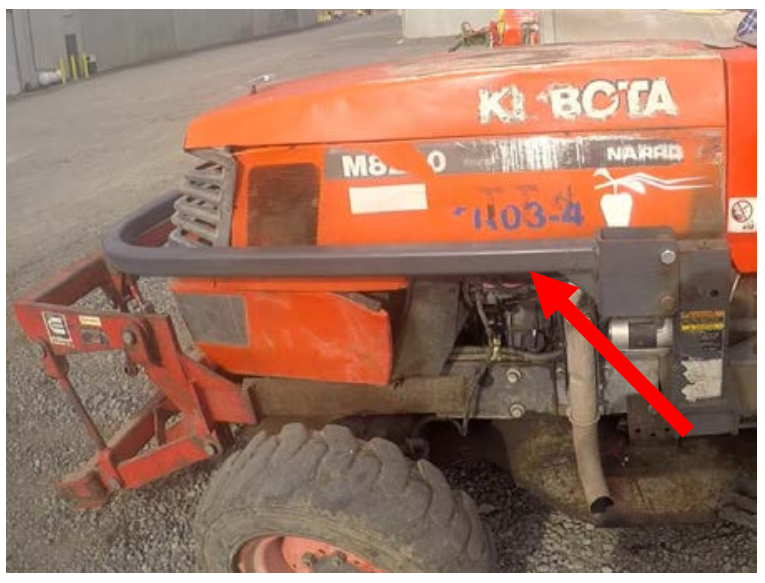

Photo 4: ROPS in folded down position 
Although the incident was not witnessed, investigators believe that the victim likely stopped the tractor and put the PTO to the mower in neutral, intending to dismount and retrieve his hat, but he did not put the tractor transmission into neutral. When he removed his foot from the clutch, the tractor may have lurched forward suddenly.

Another possibility is that he left the shuttle in the "forward" position and put the gear selector in the center of the operator's compartment (Photo 5) in the neutral position, then contacted the lever with his

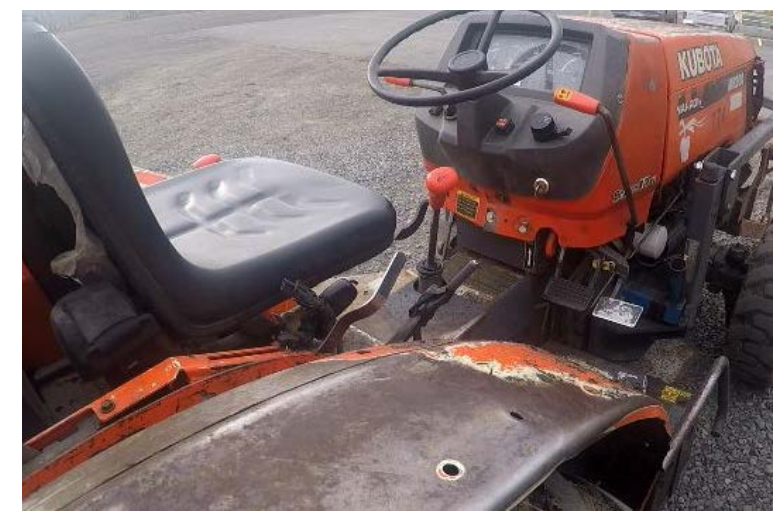

Photo 5: Gear selector placement in center of operator's compartment.

leg as he attempted to dismount, shifting the tractor into gear causing it to move forward.

An investigation of the tractor found that the gear selector moved easily between gears with little force. In either scenario, the sudden motion may have caused the victim to fall toward the rear of the tractor and down to the ground between the tractor's right rear wheel and the mower. The tractor continued moving forward, causing the mower to run over the victim's head and upper body.

\section{CONTRIBUTING FACTORS}

- The tractor was not shut off and the parking break was not set before operator attempted to dismount

- The mower was not being operated in the offset position, which is intended to help the tractor operator avoid low hanging branches and other obstacles

- Operator may have been attempting to dismount tractor from side without steps, increasing the likelihood of slipping or falling.

\section{CAUSE OF DEATH}

The death certificate listed the cause of death as "Severe head and body trauma." Postmortem toxicology tests were negative for alcohol and other drugs.

\section{RECOMMENDATIONS AND DISCUSSION}

Recommendation 1: Train operators to always shut down tractors safely before leaving the driver's seat. Ensure that they follow safety guidelines through frequent retraining and spot checks. 
Discussion: For their own safety and that of bystanders, operators should never leave the driver's seat of a tractor that is still running. Before dismounting the tractor, operators should always:

- Disengage the PTO and lower all implements to the ground

- Place all controls in the neutral position

- Place the transmission in park lock, or if a maual transmission, place in the lowest gear

- Set the parking brake(s)

- Stop the engine

- Remove the key

In this case, the victim had received tractor safety material from the employer that included information about safe shutdown. Safe tractor shutdown involves several steps. Even if workers have received tractor safety training, they might feel that following the correct procedure is inconvenient or overly cautious in a situation where they only need to briefly leave the driver's seat of the tractor. Ensure that workers understand that safe shutdown protocol must be used every time they leave the tractor, and use frequent training and spot checks to make sure safe shutdown is being practiced in the field.

During the investigation, it was found that the ignition on the tractor had been bypassed and that a starter switch had been added. This allowed the tractor to be started in gear, with the shuttle in forward or reverse. As manufactured, the tractor should only start and stop using the key. Investigators could not determine if this played any role in the incident. Operating and safety mechanisms on tractors should not be bypassed and employers should maintain tractors in a safe manner according to manufacturer's specifications.

Recommendation 2: Train operators to always mount and dismount tractors in a safe manner by using all steps and handholds available, and maintaining three points of contact.

Discussion: The victim was run over by the right side of the mower, indicating that he likely attempted to dismount the tractor from the right side, which was not equipped with

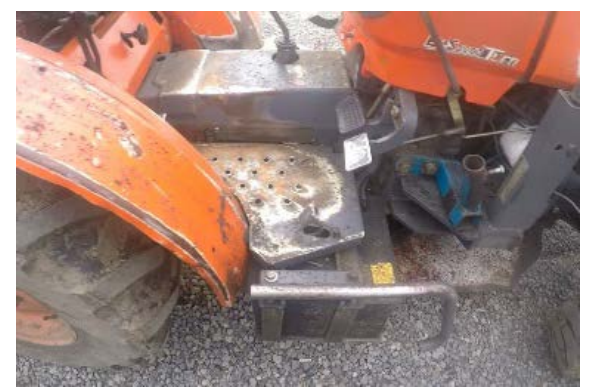

Photo 6: Right side of tractor without steps

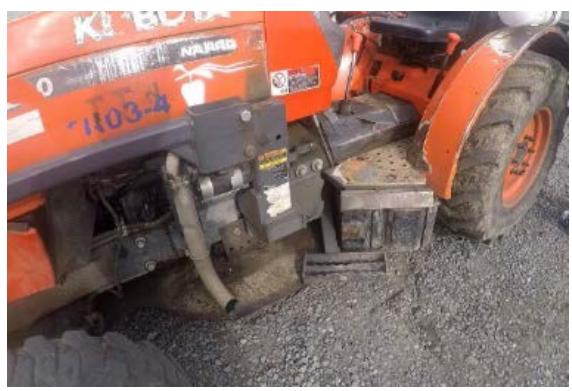

Photo 7: Left side of tractor showing step designed for mounting and dismounting built-in steps. In addition, the foot throttle pedal blocked the way for easy access or egress from this side of the tractor (Photos 6 and 7). It would not have been possible to safely dismount the tractor 
from this side, which may have contributed to his fall.

Operators should be trained to mount and dismount tractors safely. To avoid injury, getting on or off a tractor should only be done using the steps provided. Operators should not jump down from the tractor. Steps provide traction to reduce slips and their placement is designed to allow the operator to avoid inadvertently contacting controls. Three points of contact, either two hands and one foot or two feet and one hand, should always be maintained when mounting and dismounting to avoid slips or falls.

Recommendation 3: Keep clear of obstacles, such as low hanging branches, to the extent possible when operating a tractor with or without attachments.

Discussion: Based on evidence from the scene, investigators believe that as the victim was mowing grass near the trees, he was struck by a low hanging branch which knocked the hat he was wearing off of his head. The fatal incident likely occurred as he attempted to dismount the still runing tractor to retrieve the hat. Employers should train operators to identify and remove or avoid obstacles in areas they intend to operate machinery.

The rotary mower attachment that the victim was using that day was equipped with a hydraulic hitch that enabled the operator to offset the mower up to 14 inches to the side. This function was designed to allow the tractor operator to avoid obstructions, such as low hanging tree limbs, over the area being mowed. If the victim had been using this safety feature on the day of the incident to mow the grass edge closest to the pear trees, he would have been able to keep the tractor nearer to the center of the row and may not have been hit by the protruding branch. Employers should train operators and enforce proper tractor operation.

Recommendation 4: Consider using tractors equipped with operator presence sensing (OPS) technology or other interlocks that will lock out the powertrain and PTO if the operator leaves the driver's seat.

Discussion: An Operator Presence Sensing (OPS) or Operator Presence Control system (OPC) is a safety feature that keeps the tractor and PTO from moving when the operator is not in the driver's seat. Newer tractor models are often manufactured with this feature built in. When the operator leaves the driver's seat, the engine and the PTO stop running within seconds.

Never disable or bypass existing OPS systems.

The tractor that the victim was operating on the day of the incident was manufactured in 1999 without an OPS system. If one had been installed, the tractor's engine would have shut off when the victim rose out of the operator's seat while the transmission was still in gear, potentially stopping the forward movement of the tractor before the mower could strike him. 


\section{REFERENCES}

lowa State University, Environmental Health and Safety. 2016.Tractor Safety Guidelines. Retrieved from: http://publications. ehs.iastate.edu/tractorsafetyl

Harshman, W, Yoder, A, Hilton, J, \& Murphy, D. 2011. HOSTA task sheet 4.2: Tractor Hazards. Pennsylvania State University. National Safety Tractor and Machinery Operation Program. Retrieved from:

http://articles.extension.org/sites/default/files/NSTMOP\%20Task\%20Sheets\%20Section \%204\%202013 0.pdf

Kubota Tractor Corporation.1998. The Ten Commandments of Tractor Safety. Retrieved from: http://kubota.com/assets/safety/pdf/Kubota10CommandmentsTractorSafety.pdf

\section{ACKNOWLEDGEMENTS}

This report was reviewed by stakeholders from labor and business communities and various Washington State and Federal worker safety agencies. Though we are unable to acknowledge specific individuals for their contributions to this report, we would like to recognize the following for their help and support of the FACE mission and objectives:

- The Employer involved in the incident

- Safety \& Health Assessment \& Research for Prevention (SHARP)

- Division of Occupation Safety and Health (DOSH)

- Federal FACE Program Management (NIOSH)

\section{INVESTIGATOR INFORMATION}

Todd Schoonover has a PhD in Industrial Hygiene from the University of Illinois at Chicago. He is a Certified Industrial Hygienist $(\mathrm{ClH})$ and Certified Safety Professional (CSP). Todd is currently the Principal Investigator for the WA FACE program.

Randy Clark has a BA from The Evergreen State College. He is a Safety and Health Specialist with the WA FACE program.

Christina Rappin has a BA/BS from The Evergreen State College. She is a Research Investigator with the WA FACE program.

\section{WASHINGTON STATE FACE PROGRAM INFORMATION}

The Washington State Fatality Assessment and Control (WA FACE) program is one of many workplace health and safety programs administered by the Washington State Department of Labor \& Industries' Safety \& Health \& Research for Prevention (SHARP) 
program. Under a cooperative agreement with the National Institute for Occupational Safety and Health (NIOSH grant 2U60OH008487), WA FACE collects information on occupational fatalities in WA State and targets specific types of fatalities for evaluation. WA FACE investigators evaluate information from multiple sources. Findings are summarized in narrative reports that include recommendations for preventing similar events in the future. These recommendations are distributed to employers, workers, and other organizations interested in promoting workplace safety. NIOSH-funded, statebased FACE programs include: California, Kentucky, Massachusetts, Michigan, New York, Oregon, and Washington. WA FACE does not determine fault or legal liability associated with a fatal incident. Names of employers, victims and/or witnesses are not included in written investigative reports or other databases to protect the confidentiality of those who voluntarily participate in the program. Additional information regarding the WA FACE program can be obtained online at www.Lni.wa.gov/Safety/Research/FACE, or from:

\section{Washington State FACE Program}

PO Box 44330

Olympia, WA 98504-4330

1-888-667-4277 